\title{
A Novel Technique for the Fabrication of Hollow Denture - A Need for Resorbed Ridge
}

\author{
Rahul Suresh Jaiswal ${ }^{1}$, Hema Kanathila ${ }^{2}$, Anandkumar G. Patil ${ }^{3}$ \\ 1,2,3 Department of Prosthodontics, KAHER's KLE VK Institute of Dental Sciences, Belagavi, Karnataka, India.
}

\section{INTRODUCTION}

Removable prosthesis is probably one of the oldest types of dental therapy used to rehabilitate patients with complete or partial edentulousness. The main function of the edentulous alveolar ridge is to provide a major area of support for the dentures. ${ }^{1}$ Ill-fitting prosthesis leads to a condition where there is no longer adequate support of bone due to RRR. Hence, rehabilitation of such cases pose a clinical challenge, as there is a decreased denture foundation area for support, retention and stability. ${ }^{2}$

Residual ridge resorption (RRR) is the severe atrophy of alveolar bone underlying the mucoperiosteum. RRR affects the alveolar bone morphology, resulting in a decreased denture foundation area and increased inter-alveolar ridge space. The increase in inter-ridge distance provides a huge restorative space which results in a heavier complete denture due to greater volume of denture base material. This increase in restorative space amalgamates with the long lip length of the patient which gives rise to huge challenge to the success of the complete denture. Also, decreased denture foundation area increases the heaviness of the prosthesis and negatively affects the retention of the denture due to gravity. ${ }^{3}$

Various weight-reduction techniques have been used in the past using a rigid three-dimensional spacer, such as dental stone (Ackerman, 1955), cellophanewrapped asbestos, silicone putty during laboratory preparation to keep denture base content out of the intended hollow cavity of the prosthesis. The following case report describes a distinct lab technique for construction of hollow maxillary complete denture for a patient with severe RRR.

\section{PRESENTATION OF CASE}

A 69-year-old male patient registered with the chief complaint of missing teeth to the Department of Prosthodontics, KLE VK Institute of Dental Sciences, Belagavi, Karnataka. The patient's medical history was not significant. Past dental history showed that the patient has been a denture wearer for 4 to 5 years, and the maxillary prosthesis was loose. His denture was rendered twice in this period. Intraoral evaluation showed severely resorbed maxilla with increased inter-ridge space of $41 \mathrm{~mm}$. No other clinical abnormality was present.

\author{
Corresponding Author: \\ Dr. Rahul S. Jaiswal, \\ Department of Prosthodontics, \\ KAHER's KLE VK Institute of \\ Dental Sciences, Belagavi, \\ Karnataka, India. \\ E-mail: dr.jaiswal1993@gmail.com
}

DOI: $10.14260 / \mathrm{jemds} / 2021 / 480$

How to Cite This Article:

Jaiswal RS, Kanathila H, Patil AG, et al. A novel technique for the fabrication of hollow denture - a need for resorbed ridge. J Evolution Med Dent Sci 2021;10(30): 2346-2349, DOI:

$10.14260 /$ jemds/2021/480

Submission 15-03-2021,

Peer Review 21-05-2021,

Acceptance 27-05-2021,

Published 26-07-2021.

Copyright (C) 2021 Rahul Suresh Jaiswal et al. This is an open access article distributed under Creative Commons Attribution License [Attribution 4.0 International (CC BY 4.0)] 
As conventional method of denture fabrication would have resulted in a hefty complete denture and as the patient was not ready for implant surgical procedure because of economic reasons, the possible treatment plans available to implement after clinical and radiographic evaluation were a hollow maxillary complete denture and a conventional mandibular denture. This treatment was conferred in detail with the patient. After thorough examination and patient's approval the verdict was made. Mandibular complete denture was fabricated using conventional technique.

Following steps were followed for the fabrication of hollow maxillary complete denture. Try-in of maxillary complete denture (heat cure denture base) following conventional technique was done. The flask with interchangeable counter flask was used for the fabrication of hollow denture. The term "interchangeable technique" refers to a method that employs the use of one base flask with two interchangeable counter flasks.

With the exception of using admix technique at the definitive impression stage and a neutral zone impression technique at the maxillo-mandibular relation stage, all steps for conventional complete denture fabrication were followed until the try-in stage. The trial maxillary and mandibular denture was invested and dewaxed in the conventional manner. After dewaxing, the flask was separated and a $2 \mathrm{~mm}$ thick layer of modelling wax was adapted on the intaglio surface of tooth and on the buccal and lingual wall created after wax elimination. The thickness was further checked with the help of k-file. (Figure 1) The area where the thickness of wax was less, wax was added layer by layer and the area where the thickness of wax was more, it was removed by scraping with the help of carver.

After adjusting the thickness of wax, Vaseline was applied over the modelling wax surface and the trial packing was done by placing the roll of clay in between the flasks to see the space available between the intaglio surface of tooth and the denture base. A polyethylene sheet was used at the time of trial closure. Later, the flask was separated and the thickness of clay was assessed. (Figure 2) After that, separating media (cold mould seal) was applied on the entire surface of base flask including permanent denture base and clay and the second counter flasking was carried out with another counter flask which perfectly fitted the base flask.
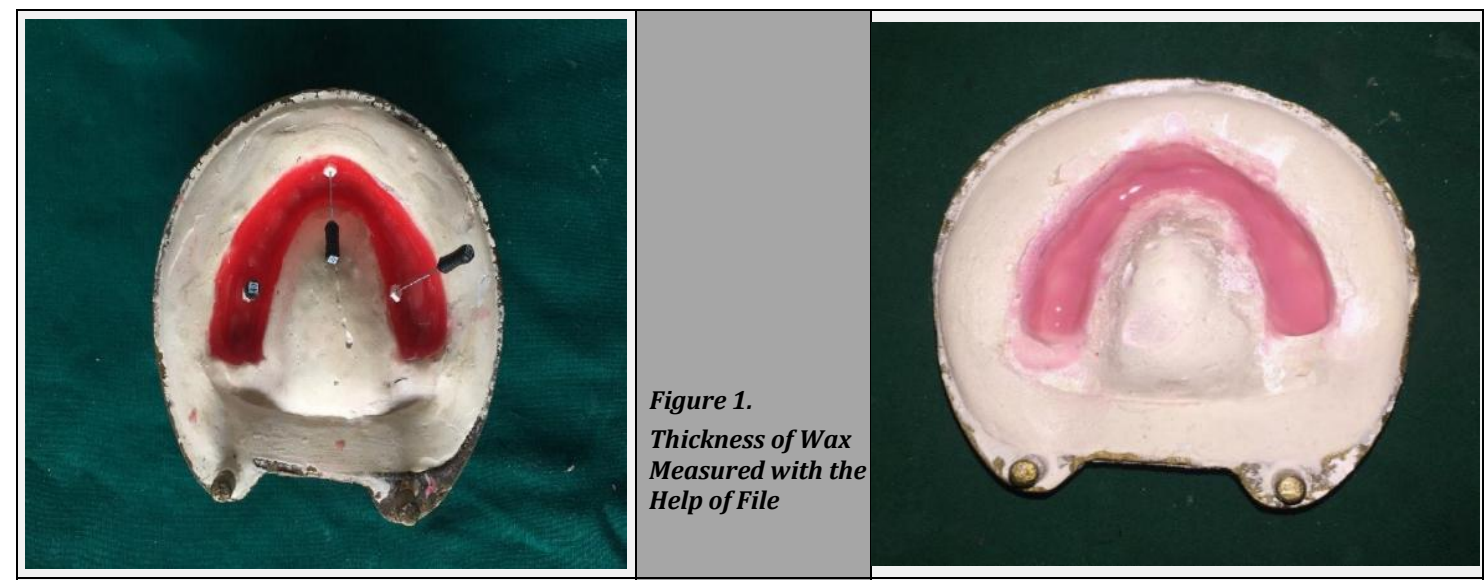

Figure 4.

Self-Cure Acrylic Shel was Prepared in the Groove Created by Removing the Clay.
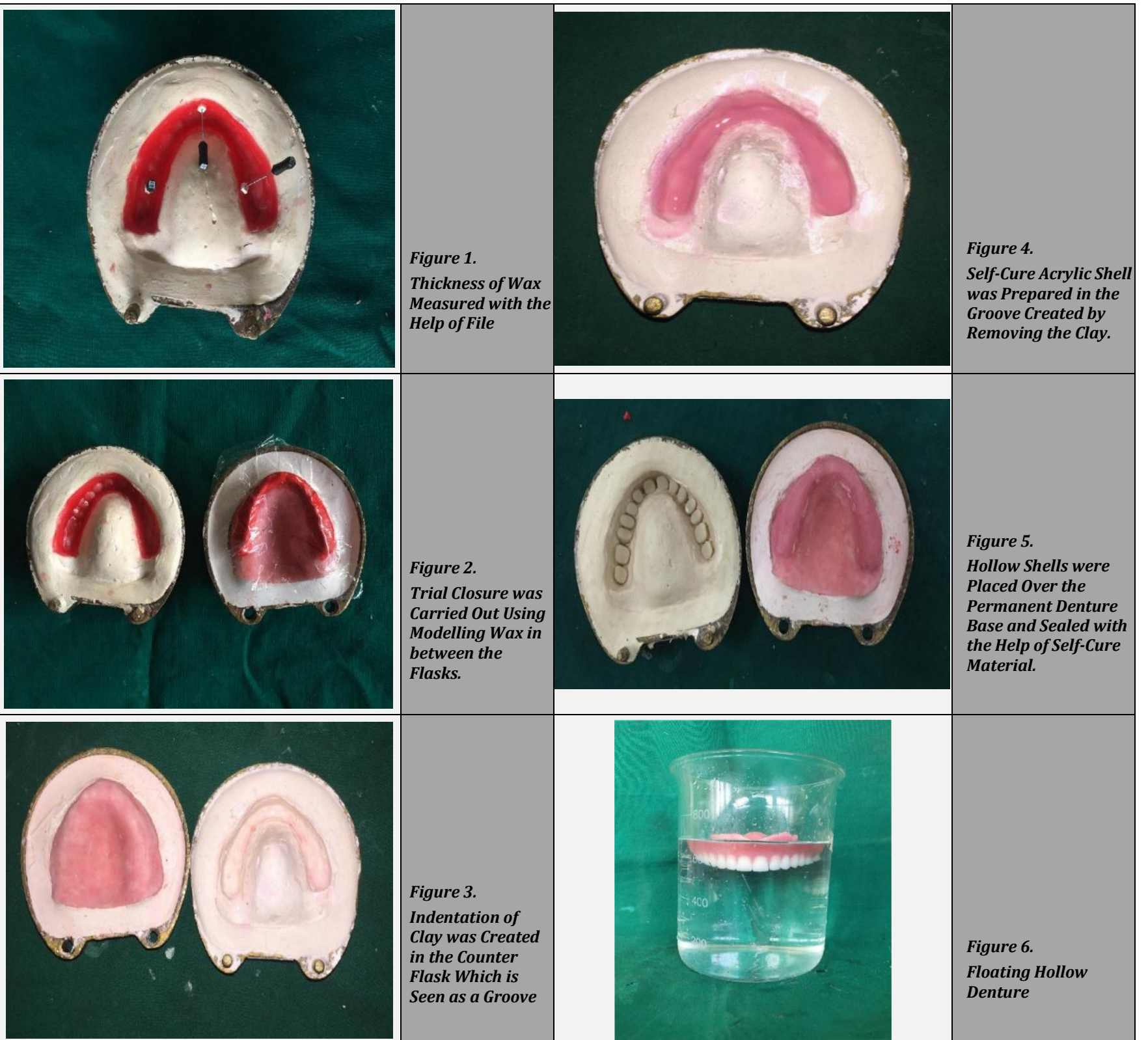

Figure 5.

Hollow Shells were Placed Over the Permanent Denture Base and Sealed with the Help of Self-Cure Material. 
The flask was separated after final setting of the dental plaster and the clay was removed (Figure 3). Later a shell of cold cure acrylic was prepared in the groove which was obtained by removing the clay from the counter flask (Figure 4). After polymerization, the self-cure acrylic resin (DPI selfcure) shell was removed from the counter flask and placed over the base flask with permanent denture base and stabilised with the help of few drops of cyanoacrylate. Trial closure of the base flask and counter flask having teeth was done to check for the hindrance while seating of flask together. Interferences present were checked with the help of articulating paper and removed by selective trimming of the tooth and acrylic shell.

After getting the proper closure between the flasks, the borders of acrylic shell were sealed with the help of self-cure acrylic resin material (Figure 5) and water dipping test was carried out to see the proper seal. After confirming the seal, final packing was carried out using heat-cure acrylic resin material (DPI heat cure). Long curing cycle was followed and later the denture was removed from the flask.

Denture was checked for adequate seal and hollowness by immersing the prosthesis in a clear jar of water. The denture was floating in the jar with water giving evidence of hollowness. The final denture was finished and polished, denture was delivered to the patient. Post insertion instructions were given to the patient.

\section{DISCUSSION}

Conventional dentures fabricated on severely resorbed ridges are unstable, non-retentive and inefficient. Also, extensive weight of prosthesis provided to patients with severe RRR can worsen the prognosis by accelerating resorption of the residual ridge. ${ }^{4}$ This may be due to the continuous pressure exerted on the residual ridge by the heavy denture even at rest. ${ }^{5}$ Systemic illness, financial problems and unwillingness for the surgery will rule out the case for implant surgical and bone augmentation procedure. Therefore, the conventional denture becomes the treatment option left in such cases. ${ }^{6}$

Bone resorption begins shortly after complete tooth extraction and continues for the rest of the patient's life. Individual variations in resorption rates are difficult to predict. Because of its complicated aetiology, it is therefore poorly known. Modification can be made to the conventional denture in addition to the modification in impression technique to prevent the bone loss. ${ }^{7}$ The foregoing literature reports that hollow dentures have been fabricated to decrease the volume of the denture material so as to prevent the problem associated with it. This ideology was supported by the study of Kalra A et al. In his study, he concluded that the denture retention and stability values of conventional dentures and hollow dentures were not found to be statistically significant. ${ }^{8}$ Also, Shah RJ et al. in her study on hollow mandibular complete denture concluded that reducing the heaviness of the dentures will prevent transmission of damaging forces to the atrophic ridge that would otherwise be transmitted from a conventional heavy prosthesis to the underlying mucosa. ${ }^{9} \mathrm{He}$ had also described an innovative technique for the construction of hollow denture using 3D printed resin spacer guide. But the drawback of this system includes cost and accessibility of 3D scanner, 3D printer and dental SG resin material. ${ }^{10}$ Some of the techniques had even tried silicone putty as a spacer for hollowing the prosthesis; however, its retrieval was a difficult prospect from the hollow cavity later on, due to its stiffness after complete polymerization of the prosthesis. ${ }^{11}$ Anchal Qanungo et al. had described a hollowing technique using glycerine soap as this does not interfere with the curing of heat cure acrylic resin as the boiling point of glycerine is $290^{\circ}$. The disadvantage being sealing the margins which could result in microleakage. ${ }^{12}$

To serve as a spacer, Chaturvedi et al. rolled dental plaster dough with pumice and sugar syrup and spread it over the heat-cured foundation. Following that, the heat cure resin was mixed, packed, and processed. A bur was used to make two narrow holes in the denture, distal to the posterior most teeth. The dental cement-pumice and sugar syrup were then scraped off and placed in water. ${ }^{13}$

This technique overcomes the drawbacks of the older techniques. Present technique maintains volume of denture without increasing the weight by "hollowing out" the denture base. The technique of using a flask with two interchangeable lids and clay was very convenient for the fabrication of hollow maxillary denture. However, inappropriate orientation of two parts of flask can lead to discrepancy.

\section{CONCLUSIONS}

Excessive ridge resorption leaves a broad restorative gap between the residual ridges. In such condition, prosthetic rehabilitation often results in increase in the prosthesis height and weight which will overload the residual alveolar ridges and indirectly jeopardising the prosthesis retention and stability.

Pre-prosthetic treatment and implant-retained prosthesis may not always be feasible options in such cases because of systemic conditions or expenses. Thus, in such situations a light-weight complete denture prosthesis is a feasible option which decreases leverages by reducing the extra load on the underlying mucosa.

Financial or other competing interests: None.

Disclosure forms provided by the authors are available with the full text of this article at jemds.com.

\section{REFERENCES}

[1] Singh OP, Kaur R, Nanda SM, et al. Residual ridge resorption: a major oral disease entity in relation to bone density. Indian J Oral Sci 2016;7(1):3-6.

[2] Bhat AM. A hollow complete denture for severely resorbed mandibular ridges. J Indian Prost Soc 2006;6(3):157-61.

[3] O’Sullivan M, Hansen N, Cronin RJ, et al. The hollow maxillary complete denture: a modified technique. J Prosthet Dent 2004;91(6):591-4.

[4] Brennom EF. Adding weight may promote retention of lower denture. Dental Survey 1973;49(3):30.

[5] Nakashima K, Sato T, Hara T, et al. An experimental study on histopathological changes in the tissue covered with 
denture base without occlusal pressure. J Oral Rehabil 1994;21(3):263-72.

[6] Madhumathi V, Devi MKP. Rehabilitation of atrophic maxilla with a hollow maxillary complete denture: a case report. Journal of Indian Academy of Dental Specialist Researchers 2014;1(1):28-30.

[7] Ohkubo C, Hosoi T. Effect of weight change of mandibular complete dentures on chewing and stability: a pilot study. J Prosthet Dent 1999;82(6):636-42.

[8] Kalra A, Dhull KS, Iyer SR, et al. Does hollowing of complete denture enhance retention?-a pilot study. J Clin Diagn Res 2015;9(5):ZC44-7.

[9] Shah RJ, Lagdive SB, Shah SR, et al. Management of severely atrophic mandibular ridge using hollow denture with an analytical discussion: a clinical case report. J Clin Diagn Res 2017;11(4):ZD26-9.

[10] Shah RJ, Lagdive SB, Machchhar AH, et al. Technique to fabricate hollow maxillary complete denture using 3D printed template. J Prosthod 2020;29(4):360-3.

[11] Manoj SS, Chitre V, Aras M. Management of compromised ridges: a case report. J Indian Prosthodont Soc 2011;11(2):125-9.

[12] Qanungo A, Aras MA, Chitre V, et al. An innovative and simple technique of hollow maxillary complete denture fabrication. J Clin Diagn Res 2016;10(8):ZD23-5.

[13] Jaiswal PR, Pande N, Banerjee R, et al. Hollow denture: a boon in increased interridge space in edentulous ridges. Indian J Multidiscip Dent 2017;7(2):144-8. 